\title{
PENGELOMPOKAN DATA PELAYANAN KESEHATAN DI KOTA MAKASSAR MENGGUNAKAN WARD'S METHOD
}

\section{Clustering of Health Care Data in Makassar City Using Ward's Method}

\author{
Isma Muthahharah ${ }^{1 *}$, Agusalim Juhari ${ }^{2}$ \\ 1,2 Prodi Pendidikan Matematika STKIP Pembangunan Indonesia \\ Jln. Inspeksi Kanal Citraland No. 10, Makassar, 90222, Indonesia \\ e-mail:1* muthahharahisma@gmail.com ; 2 agusalimjuhari@gmail.com \\ Corresponding Author*
}

\begin{abstract}
Abstrak
Dalam pelayanan kesehatan, kualitas pelayanan menempatkan pasien sebagai pihak yang mengkomsumsi dan menikmati jasa pelayanan kesehatan termasuk yang paling menentukan kualitas jasa kesehatan. Dinas kesehatan Kota Makassar mencatat bahwa masyarakat yang terlayani di tahun 2018 mencapai 81,77\% dibanding tahun 2017 yang hanya 81,71 \%. Data yang dikeluarkan oleh dinas kesehatan belum menunjukkan secara spesifik tentang kecamatan mana yang mempunyai pelayanan kesehatan yang sangat baik, cukup baik, dan kurang baik pada masa pandemi covid-19. Oleh karena itu, diperlukan suatu metode pengelompokkan yaitu ward's method. Pelayanan kesehatan dalam penelitian ini meliputi rumah sakit, puskesmas, home care dan Telemedicine di 15 lokasi kecamatan, Berdasarkan hasil analisis terbentuk 3 cluster, yaitu cluster 1 dengan anggota kecamatan Biringkanaya, Bontoala, Makassar, Manggala, Tallo, Tamalanrea, dan Wajo yang mempunyai pelayanan kesehatan yang cukup baik. cluster 2 dengan anggota kecamatan yaitu Mamajang, Panakkukang, Rappocini, Ujung Pandang, dan kepulauan sangkarang yang mempunyai pelayanan kesehatan yang sangat baik, cluster 3 dengan anggota Kecamatan Mariso, Tamalate dan Ujung Tanah yang mempunyai pelayanan kesehatan yang kurang baik.
\end{abstract}

Kata Kunci : cluster, ward's, method, Kesehatan, Makassar

\begin{abstract}
In health services, the quality of service places patients as the party who consumes and enjoys health services, including those that most determine the quality of health services. The Makassar city health office noted that the people served in 2018 reached $81.77 \%$ compared to 2017 which was only $81.71 \%$. The data released by the health department have not shown specifically which districts had very good, pretty good, and poor health services during the Covid-19 pandemic. Therefore, we need a classification method, namely the ward's method. Health services in this study include hospitals, health centers, home care and telemedicine in 15 sub-district locations. Based on the results of the analysis formed 3 clusters, namely cluster 1 with members of the sub-districts of Biringkanaya, Bontoala, Makassar, Manggala, Tallo, Tamalanrea, and Wajo which have pretty good health services. cluster 2 with sub-district members namely Mamajang, Panakkukang, Rappocini, Ujung Pandang, and Sangkarang Islands which have very good health services, cluster 3 with members of Mariso, Tamalate and Ujung Tanah sub-districts which have poor health services.
\end{abstract}

Keywords: cluster, ward method, health, Makassar 


\section{PENDAHULUAN}

Dalam pelayanan kesehatan, kualitas pelayanan menempatkan pasien sebagai pihak yang mengkomsumsi dan menikmati jasa pelayanan kesehatan termasuk yang paling menentukan kualitas jasa kesehatan [1]. Kondisi pelayanan di Kota Makassar semakin meningkat seiring dengan meningkatnya kepuasan masyarakat setempat. Dinas terkait mencatat, masyarakat terlayani di tahnu 2018 mencapai 81,77 $\%$ dibanding tahun 2017 yang hanya 81,71 \% [2]. Data yang dikeluarkan oleh dinas terkait belum menunjukkan secara spesifik tentang kecamatan mana yang mempunyai pelayanan kesehatan yang sangat baik, cukup baik, dan kurang baik pada masa pandemi covid-19, oleh karena itu dibutuhkan pengelompokkan pelayanan kesehatan.

Berdasarkan penelitian tentang gambaran mutu pelayanan rawat inap bersertifikat ISO mempertahankan aspek yang di anggap pasien puas dengan pelayanan yang diberikan dan dapat melakukan perbaikanperbaikan yang di anggap pasien belum puas dengan pelayanan yang diberikan [3]. Selanjutnya [4] tentang analisis pengaruh dimensi kualitas pelayanan pada kepuasan pasien rawat inap di Rumah Sakit Bhayangkara, dengan hasil penelitian adalah kualiatas pelayanan berupa keandalanan, ketanggapan, kepastian, kepedulian dan bukti nyata yang secara simultan berpengaruh positif pada kepuasan pasien rawat inap di rumah sakit bhayangkara. Beberapa penelitian tersebut belum ada yang menggambarkan secara umum tentang pelayanan kesehatan terhadap kepuasan masyarakat di rumah Sakit, puskesmas, home care, dan telemedicine. Oleh karena itu, peneliti akan melakukan pengelompokkan pelayanan kesehatan dengan ward'method. Ward's method adalah metode clustering hirarki yang bersifat agglomerative untuk memperoleh cluster yang memiliki varian internal sekecil mungkin. Agglomerative merupakan pengelompokkan hirarki dimana setiap objek berawal dari cluster yang terpisah. Cluster dibentuk dengan mengelompokkan objek ke dalam cluster yang semakin banyak objek yang menjadi anggotanya [5]. Dua objek akan digabungkan jika mempunyai fungsi objektif terkecil diantara kemungkinan yang ada, dimana sum of squared error (SSE) digunakan sebagai fungsi objektif [6] dengan ukuran kehomogenan antara dua objek berdasarkan jumlah kuadrat kesalahan minimal [7]. Kriteria pemilihan cluster terbaik dilakukan dengan melihat nilai koefisien determinasi dan internal cluster dispersion rate (icd rate). Koefisien determinasi adalah suatu ukuran yang menunjukkan besaran kontribusi yang di berikan oleh setiap variabel pada cluster yang terbentuk. Sedangkan hasil pengelompokkan semakin baik diindikasikan oleh icd rate yang kecil [8].

Jenis pelayanan kesehatan yang digunakan pada penelitian ini yaitu puskesmas, rumah Sakit, home care dan telemedicine. Puskesmas sebagai pusat pelayanan kesehatan starata pertama yang menyelenggarakan kegiatan pelayanan pertama secara menyeluruh [9]. Sistem informasi kesehatan yang diterapkan di Puskemas Kota Makassar adalah sistem informasi manajemen kesehatan berbasis web yaitu E-Puskesmas. E-Puskesmas bertujuan untuk meningkatkan kinerja puskesmas mulai dari digitalisasi proses pelayanan, kemudahan pembuatan dan pengiriman laporan [10]. Rumah Sakit adalah institusi pelayanan kesehatan yang menyelenggarakan pelayanan kesehatan perorangan secara paripurna, yang menyediakan pelayan rawat inap, rawat jalan, dan gawat darurat [11].Peningkatan mutu suatu organisasi sangat bergantung pada pelayanan lesehatan yang diberikan kepada masyarakat, untuk itu dibutuhkan suatu pengembangan model manajemen yang baik untuk digunakan dalam pengembangan rumah sakit di Kota Makassar [12]. Home Care adalah pelayanan kesehatan yang berkesinambungan dan komperhensif yang diberikan kepada individu dan keluarga di tempat tinggal [13].Tujuan dari home care adalah untuk meningkatkan, mempertahankan atau memulihkan kesehatan atau memaksimalkan tingkat kemandirian dan meminimalkan komplikasi akibat dari penyakit serta pemenuhan kebutuhan dasar pasien dan keluarga [14]. Pada tahun 2014 makassar berhasil mengembangkan telemedicine yang merupakan layanan kesehatan gratis [15]. Telemedicine adalah transfer data medik elektronik dari satu lokasi ke lokasi lainnya dan dilakukan dari jarak jauh[2].

\section{METODE PENELITIAN}

\subsection{Sumber Data}

Data yang digunakan adalah data sekunder, yaitu data yang diperoleh langsung dari dinas kesehatan Kota Makassar pada masa pandemi covid-19. Objek pada penelitian ini adalah 15 kecamatan di Kota Makassar, dengan rincian yaitu Biringkanaya, Bontoala, Makassar, Mamajang, Manggala, Mariso, Panakkukang, Rappocini, Tallo, Tamalanrea, Tamalate, Ujung Pandag, Ujung Tanah, Wajo, dan Kepulauan Sangkarang. Setiap variabel diukur dalam skala ordinal dengan 3 kategori yaitu sangat baik, cukup baik dan kurang baik. Variabel yang digunakan adalah persentase pelayanan kesehatan rumah sakit $\left(X_{1}\right)$, persentase pelayanan 
kesehatan puskesmas $\left(X_{2}\right)$, persentase pelayanan kesehatan home care $\left(X_{3}\right)$, persentase pelayanan kesehatan telemedicine $\left(X_{4}\right)$ dengan defenisi operasional variabel adalah sebagai berikut:

Tabel 1. Defenisi Operasional Variabel

\begin{tabular}{llll}
\hline No & \multicolumn{1}{c}{ Variabel } & \multicolumn{1}{c}{ Definisi Operasional } \\
\hline 1 & $\begin{array}{l}\text { Persentase pelayanan } \\
\text { rumah sakit }\left(X_{1}\right)\end{array}$ & kesehatan & $\begin{array}{l}\text { rata-rata persentase pelayanan rumah sakit yang meliputi pelayanan } \\
\text { rawat inap, pelayanan farmasi, pelayanan laboratorium, dan } \\
\text { pelayanan administrasi }\end{array}$ \\
\hline 2 & $\begin{array}{l}\text { Persentase pelayanan } \\
\text { puskesmas }\left(X_{2}\right)\end{array}$ & kesehatan & $\begin{array}{l}\text { rata-rata persentase pelayanan puskesmas yang meliputi pelayanan } \\
\text { kesehatan ibu dan anak, pelayanan farmasi, pelayanan administrasi, } \\
\text { dan pelayanan rawat inap. }\end{array}$ \\
\hline 3 & $\begin{array}{l}\text { Persentase pelayanan } \\
\text { home care }\left(X_{3}\right)\end{array}$ & kesehatan & $\begin{array}{l}\text { raata-rata persentase pelayanan home care yang meliputi pelayanan } \\
\text { pada umur lansia (lanjur usia), pelayanan pasca operasi, pelayananan } \\
\text { pada disabilitas, dan pelayanan penyakit kronis }\end{array}$ \\
\hline 4 & $\begin{array}{l}\text { Persentase pelayanan } \\
\text { telemedicine }\left(X_{4}\right)\end{array}$ & kesehatan & $\begin{array}{l}\text { rata-rata persentase pelayanan telemedicine yang meliputi pelayanan } \\
\text { pemeriksaan fisik tertentu, pelayanan pemberian obat dan pelayanan } \\
\text { pemberian surat rujukan untuk pemeriksaan lebih lanjut }\end{array}$ \\
\hline
\end{tabular}

\subsection{Prosedur Analisis}

Prosedur analisis yang dilakukan adalah sebagai berikut:

1. Melakukan analisis data secara deskriptif.

2. Melakukan pengelompokkan dengan ward's method dengan persamaan berikut:

$$
S S E=\sum_{j=1}^{p}\left(\sum_{i=1}^{n}-\left(\frac{1}{n} \sum_{i=1}^{n} X_{i j}\right)^{2}\right)
$$

3. Menentukan hasil cluster terbaik berdasarkan nilai koefisien determinasi $\left(R^{2}\right)$ dan icd rate dengan persamaan berikut:

dengan,

$$
R^{2}=\frac{(S S T-S S W)}{S S T}
$$

$$
\begin{gathered}
S S T=\sum_{i=1}^{n_{c}} \sum_{j=1}^{c} \sum_{k=1}^{p}\left(x_{i j}^{k}-\overline{x^{k}}\right)^{2} \\
S S W=\sum_{i=1}^{n_{c}} \sum_{j=1}^{c} \sum_{k=1}^{p}\left(x_{i j}^{k}-\overline{x_{J}^{k}}\right)^{2} \\
\text { icd rate }=1-R^{2}
\end{gathered}
$$

4. Menganalisis karakteristik hasil cluster yang terbentuk

\section{HASIL DAN PEMBAHASAN}

\subsection{Statistika Deskriptif}

Statistika deskriptif yang digunakan dalam penelitian ini meliputi nilai minimum, maksimum, mean dan standar deviasi dari persentase pelayanan kesehatan yang terdiri dari puskesmas, rumah sakit, home care dan telemedicine yang disajikan pada Tabel 2.

Tabel 2. Statistika Deskriptif

\begin{tabular}{lccccc}
\hline & N & Minimum & Maximum & Mean & Std. Deviation \\
\hline Puskesmas & 15 & 52 & 100 & 78,67 & 12,821 \\
\hline Rumah Sakit & 15 & 66 & 100 & 83,07 & 9,098 \\
\hline Home care & 15 & 68 & 100 & 84,40 & 1,469 \\
\hline Telemedicine & 15 & 50 & 100 & 73,73 & 13,025 \\
\hline
\end{tabular}

Berdasarkan Tabel 2, terlihat secara umum bahwa variabel home care dan telemedicine memiliki mean (rata-rata) tertinggi yang dapat dikatakan pelayanan lansia, pelayanan pasca operasi disabilitas dan pelayanan kronis sangat baik serta pelayanan pemeriksaan fisik tertentu, pelayanan pemberian obat dan pelayanan 
pemberian surat rujukan untuk pemeriksaan lebih lanjut juga sangat baik. Sebaliknya puskesmas dan rumah sakit memilki mean (rata-rata) terendah yang dapat dikatakan pelayanan rawat inap, pelayanan farmasi, pelayanan laboratorium, pelayanan administrasi, pelayanan keluarga berencana serta pelayanan kesehatan ibu dan anak yang kurang baik.

\subsection{Pengelompokkan dengan Ward's Method}

Berdasarkan ward's method, nilai koefisien determinasi untuk pembentukan cluster 1, 2, dan 3 dapat dilihat pada Tabel.

Tabel 3. Nilai Koefisien Determinasi dan icd rate

\begin{tabular}{ccc}
\hline cluster & Koefisien determinasi & icd rate \\
\hline 1 & 0,987 & 0,012 \\
\hline 2 & 0,992 & 0,008 \\
\hline 3 & 0,984 & 0,016 \\
\hline
\end{tabular}

Berdasarkan Tabel 3, terlihat bahwa pengelompokkan sebanyak 3 cluster menunjukkan pengelompokkan yang optimal.yang disajikan pada Gambar 1.

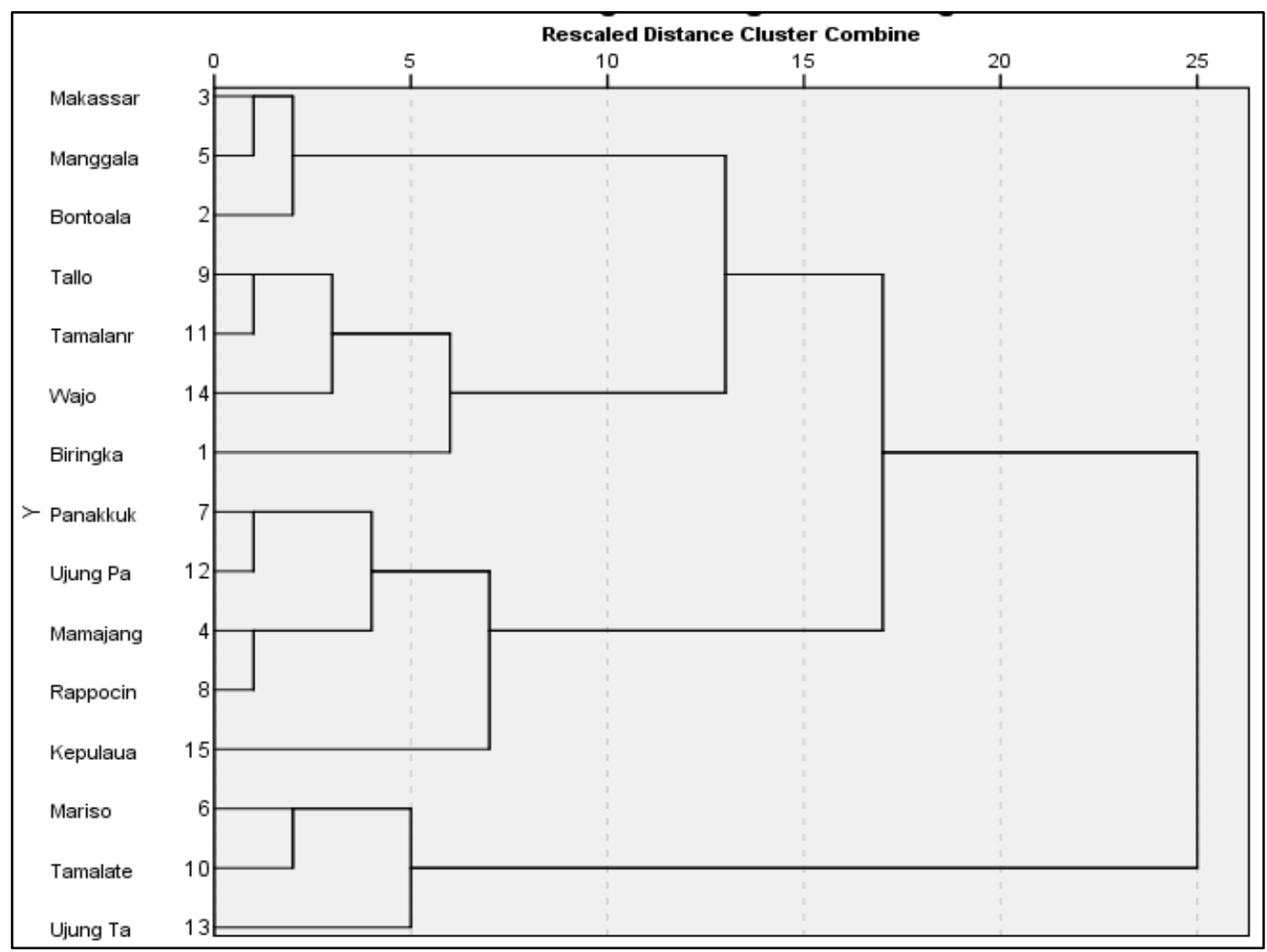

Gambar 1. Dendogram Ward's Method

Berdasarkan Gambar 1 menunjukkan 3 cluster yang terbentuk yaitu cluster 1 dengan anggota kecamatan Makassar, Manggala, Bontoala, Tallo, Tamalanrea, Wajo dan Biringakanaya. Cluster 2 dengan anggota Kecamatan Panakukkang, Ujung Pandang, Mamajang, Rapocini, dan Kepulauan Sangkarang, Cluster 3 dengn anggota kecamatan Mariso, Tamalate dan Ujung Tanah.

\subsection{Karakteristik Cluster}

Karakteristik dari setiap cluster pelayanan kesehatan yang terbentuk dari 3 cluster disajikan pada Tabel 4, berikut: 
Tabel 4. Karakteristik Cluster

\begin{tabular}{|c|c|}
\hline Cluster & Karakteristik \\
\hline $\begin{array}{l}\text { Cluster 1: Kecamatan } \\
\text { Makassar, Manggala, } \\
\text { Bontoala, Tallo, Tamalanrea, } \\
\text { Wajo dan Biringkanaya }\end{array}$ & $\begin{array}{l}\text { Memilki kualitas pelayanan rumah sakit, } \\
\text { puskesmas, home care dan telemedicine } \\
\text { yang cukup baik }\end{array}$ \\
\hline $\begin{array}{l}\text { Cluster 2: Kecamatan } \\
\text { Panakkukang, Mamajang, } \\
\text { Rapocini, dan kepulauan } \\
\text { Sangkarang }\end{array}$ & $\begin{array}{l}\text { Memilki kualitas pelayanan rumah sakit, } \\
\text { puskesmas, home care dan telemedicine } \\
\text { yang sangat baik }\end{array}$ \\
\hline $\begin{array}{l}\text { Cluster 3: Kecamatan Mariso, } \\
\text { Tamalate, dan Ujung Tanah }\end{array}$ & $\begin{array}{l}\text { Memilki kualitas pelayanan rumah sakit, } \\
\text { puskesmas, home care dan telemedicine } \\
\text { yang kurang baik }\end{array}$ \\
\hline
\end{tabular}

Hasil pengelompokkan pelayanan kesehatan tersebut disajikan dalam bentuk peta seperti ditampilkan pada Gambar 2. Kualitas pelayanan rumah sakit, puskesmas, home care dan telemedicine yang cukup baik digambarkan dengan warna biru. Sedangkan kualitas pelayanan rumah sakit, puskesmas, home care dan telemedicine yang sangat baik digambarkan dengan warna ungu. Selain itu, kualitas pelayanan rumah sakit, puskesmas, home care dan telemedicine yang kurang baik digambarkan dengan warna hijau. Hal tersebut menunjukkan tingkat kualitas pelayanan kesehatan di masing-masing kecamatan di Kota Makassar.

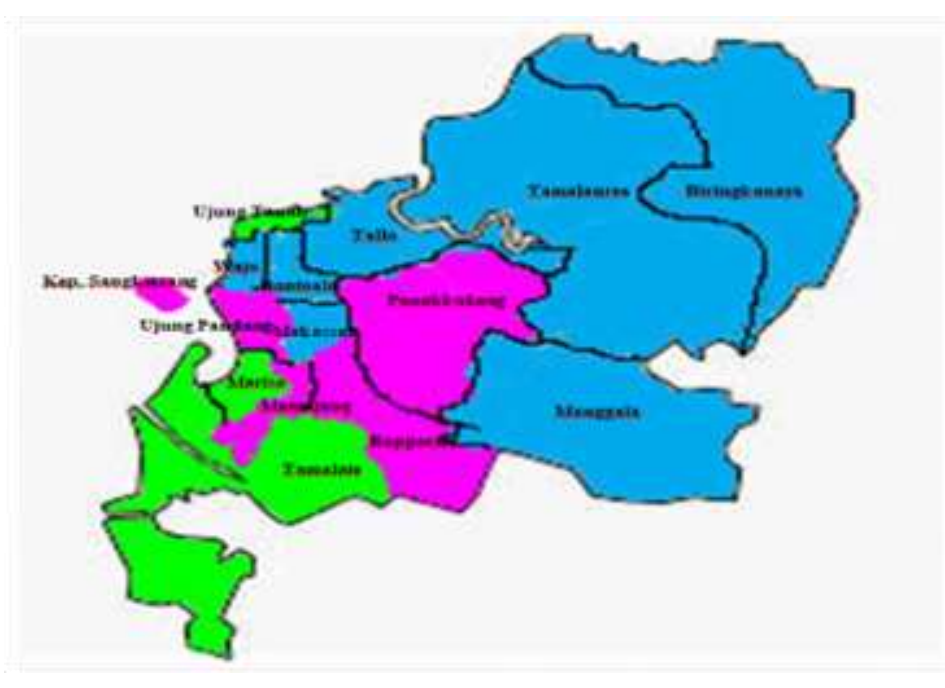

Gambar 2. Peta cluster Kecamatan Berdasarkan Pelayanan Kesehatan di Kota Makassar

\section{KESIMPULAN}

Kesimpulan yang di peroleh dari analisis menggunakan ward's method yaitu terbentuk 3 cluster (kelompok), yaitu cluster 1 dengan anggota Kecamatan Biringkanaya, Bontoala, Makassar, Manggala, Tallo, Tamalanrea, dan wajo yang mempunyai pelayanan kesehatan yang cukup baik. Cluster 2 dengan anggota kecamatan yaitu Mamajang, Panakkukang, Rappocini, Ujung Pandang, dan kepulauan sangkarang yang mempunyai pelayanan kesehatan yang sangat baik. Cluster 3 dengan anggota Kecamatan Mariso, Tamalate dan Ujung Tanah yang mempunyai pelayanan kesehatan yang kurang baik.Pada penelitian ini hanya menggunakan satu metode hierarki, oleh karena itu di perlukan metode hierarki lain dan metode non-hierarki untuk membantu proses pengelompokkan fasilitas pelayanan kesehatan di Kota Makassar.

\section{UCAPAN TERIMA KASIH}

Ucapan terimakasih ditujukan kepada Direktorat Riset dan Pengabdian Masyarakat (DRPM) yang telah memberikan hibah penelitian, tak lupa juga kepada pihak STKIP Pembangunan Indonesia yang telah memberi dukungan agar penelitian ini terealisasi dengan baik. 


\section{DAFTAR PUSTAKA}

[1] A. Alim, N. Tangdilambi, and A. Badwi, "Jurnal Kualitas Pelayanan Kesehatan (Studi Analitik Terhadap Pasien Rawat Jalan di RSUD Makassar),” J. Manaj. Kesehat. Yayasan RS.Dr. Soetomo, vol. 5, no. 2, p. 165, 2019, doi: 10.29241/jmk.v5i2.164.

[2] M. K. dr. Hj.A. Naisyah T. AZIKIN, "Pelayanan Tekemedicine Kota Makassar." 1387, [Online]. Available: http://www.ghbook.ir/index.php?name\&option=com_dbook\&task=readonline\&book_id=13629\&page=108\&c hkhashk $=03$ C $706812 \mathrm{~F} \&$ Itemid $=218 \&$ lang $=$ fa\&tmpl=component.

[3] M. Rusmin, S. Aeni, and A. F. Yuliarma, "Gambaran Mutu Pelayanan Rawat Inap Puskesmas Bersertifikasi ISO di Kota Makassar Tahun 2016,” Al-Sihah Public Heal. Sci. J., vol. 8, pp. 22-28, 2016.

[4] Nasyrah, Darwis, and Hasmin, "Analisis Pengaruh Dimensi Kualitas Pelayanan Terhadap," J. Mirai Manag., vol. 2, pp. 133-148, 2017.

[5] M. N. \& N. S. Sela Oktavia, "Pengelompokan Kinerja Dosen Jurusan Matematika Fmipa Untan Menggunakan Metode Ward," Bul. Ilm. Mat. Stat. dan Ter., vol. 02, no. 2, pp. 93-100, 2013.

[6] A. N. Fathia, R. Rahmawati, and Tarno, "Analisis Klaster Kecamatan Di Kabupaten Semarang Berdasarkan Potensi Desa Menggunakan Metode Ward Dan Single Linkage," J. Gaussian, vol. 5, no. 4, pp. 801-810, 2016.

[7] L. Rahmawati, . "Analisis Kelompok dengan Menggunakan Metode Hierarki untuk Pengelompokan Kabupaten/Kota di Jawa Timur Berdasarkan Indikator Kesehatan," SKRIPSI Jur. Mat. MIPA UM, 2013.

[8] M. Huda, "Pengelompokan Mini Market Berdasarkan Tingkat Kepatuhan Terhadap Protokol Kesehatan Menggunakan Perbandingan Hierarki dan Non-Hierarki," vol. 2019, pp. 1-14, 2021.

[9] N. Sanah, "Pelaksanaan Fungsi Puskesmas (Pusat Kesehatan Masyarakat) Dalam Meningkatkan Kualitas Pelayanan Kesehatan Di Kecamatan Long Kali Kabupaten Paser," eJournal Ilmu Pemerintah., vol. 5, no. 1, pp. 305-314, 2017, [Online]. Available: http://ejournal.ip.fisip-unmul.ac.id/site/wp-content/uploads/2017/03/Nor Sanah (03-01-17-09-15-45).pdf.

[10] D. S. Damayanti, M. Rusmin, and Z. Arranury, "Gambaran Penerapan Sistem Informasi Manajemen Kesehatan Berbasis WEB di Puskesmas Kota Makassar Tahun 2015,” Al-Sihah Public Heal. Sci. J., vol. 7, no. 2, p. 6, 2015.

[11] Kementerian Kesehatan RI, "Peraturan Menteri Kesahatan," N. Engl. J. Med., vol. 372, no. 2, pp. 2499-2508, 2018,[Online].Available:http://www.ncbi.nlm.nih.gov/pubmed/7556065\%0Ahttp://www.pubmedcentral.nih.go v/articlerender.fcgi?artid=PMC394507\%0Ahttp://dx.doi.org/10.1016/j.humpath.2017.05.005\%0Ahttps://doi.or g/10.1007/s00401-018-1825-z\%0Ahttp://www.ncbi.nlm.nih.gov/pubmed/27157931.

[12] N. Hidayah, "Model Manajemen Mutu Terpadu Pelayanan Kesehatan Untuk Pengembangan Rumah Sakit Umum Daerah Kota Makassar," J. Adm. Publik, vol. 5, no. 1, pp. 20-30, 2015.

[13] K. E. Spannow, "Efektivitas Penggunaan Layanan HomeCare Dalam Pelayanan Kesehatan PAda Puskesmas Barombong Kota Makassar," Nord. Stud. Alcohol Drugs, vol. 15, no. 1, pp. 3-4, 1998, doi: $10.1177 / 145507259801500104$.

[14] R. Fahrepi, S. Rate, and A. J. Hadi, "Hubungan Kualitas Pelayanan Homecare dengan tingkat Puskesmas Batua Kota Makassar The Relation Of Home Care Service Quality And Family's Patient Statisfaction In Batua Public Health Center Jobs Area, Makassar City," Promot. J. Kesehat. Masy., vol. 9, no. 0451, pp. 122-128, 2019, [Online]. Available: https://jurnal.unismuhpalu.ac.id/index.php/PJKM/article/viewFile/589/482.

[15] D. Indria, M. Alajlani, and H. Sf. Fraser, "Clinicians perceptions of a telemedicine system: a mixed method study of Makassar City, Indonesia," BMC Med. Inform. Decis. Mak., vol. 20, no. 1, pp. 1-8, 2020, doi: 10.1186/s12911020-01234-7. 